\title{
Do Social Conflicts With Customers at Work Encroach Upon Our Private Lives? A Diary Study
}

\author{
Judith Volmer \\ University of Erlangen \\ Sabine Sonnentag \\ University of Mannheim
}

\author{
Carmen Binnewies \\ University of Mainz \\ Cornelia Niessen \\ University of Erlangen
}

\begin{abstract}
Social interactions at work can strongly influence people's well-being. Extending past research, we examined how social conflicts with customers at work (SCCs) are related to employees' well-being (i.e., state negative affect, NA) and nonwork experiences (i.e., psychological detachment from work and negative work reflection at home) on a daily level. Using experience-sampling methodology, we collected data from 98 civil service agents over 5 working days. Hierarchical linear modeling revealed that on the daily level, SCCs were related to employees' NA as well as with their nonwork experiences. Specifically, SCCs were negatively related to psychological detachment from work and positively related to negative work reflection after work. Furthermore, results provide support for the mediating role of NA in the SCC-nonwork experiences relationship. The findings of the present study broaden the scope of workplace conflict research by showing that conflicts are not only associated with employees' impaired well-being but even encroach on their nonwork experiences.
\end{abstract}

Keywords: social conflicts with customers, recovery, psychological well-being, psychological detachment from work, negative work reflection

Other people can have a strong impact on how we feel; for example, they influence whether we feel safe and empowered or threatened and drained (Cialdini, 2001). At work, negative social interactions (i.e., social conflicts) have been suggested to be the most severe work stressors (Spector \& Jex, 1998). Past research has linked social conflicts at work with numerous negative outcomes, such as decreased organizational commitment and job satisfaction and higher turnover intentions (Frone, 2000; Spector \& Jex, 1998; Thomas, Bliese, \& Jex, 2005). Moreover, researchers have shown negative effects from social workplace conflicts on employees' health and well-being (Bolger, DeLongis, Kessler, \& Schilling, 1989; De Dreu \& Beersma, 2005). For example, employees who experience high levels of social conflict at work report higher levels of anxiety and depression (Spector \& Jex, 1998), burnout symptoms

Judith Volmer and Cornelia Niessen, Department of Psychology and Sport Sciences, University of Erlangen, Erlangen, Germany; Carmen Binnewies, Institute of Psychology, University of Mainz, Mainz, Germany; Sabine Sonnentag, Department of Psychology, University of Mannheim, Mannheim, Germany.

This research was funded by a postdoctoral research grant from the University of Erlangen that is gratefully acknowledged. We thank Iris Hartmann, Simone Pfeifle, Miriam Rohe, Juliane Wagner, and Beatrix Winter for their help in data collection. We are also grateful to Charlotte Fritz for her sound advice at an early stage of the project, as well as Andrea E. Abele and Daniel Spurk for very helpful comments on a version of this article.

Correspondence concerning this article should be addressed to Judith Volmer, University of Erlangen, Bismarckstr. 6, Erlangen, Germany D 91054. E-mail: judith.volmer@sozpsy.phil.uni-erlangen.de
(De Dreu, van Dierendonck, \& Dijkstra, 2004), and negative affect (Ilies, Johnson, Judge, \& Keeney, 2011).

In today's work environment with an increasing number of employees working in the service sector (International Labour Office, 2007), knowledge about the immediate effects of social conflicts with customers (SCCs) on employees' well-being is needed to guarantee excellent customer services as well as organizational effectiveness and survival (Grandey, Kern, \& Frone, 2007; Mueller \& Tschan, 2011; Sliter, Pui, Sliter, \& Jex, 2011). Compared with other types of social conflict (e.g., coworker or supervisor conflict), SCCs are especially harmful for employees (Grandey et al., 2007; Sliter et al., 2011; Totterdell \& Holman, 2003) because they are mostly one-shot occasions of interactions with often no opportunity to resolve the conflict after the incident. In addition, employees in the service sector also often have to engage in emotional labor (EL; Hochschild, 1983), publicly expressing emotions while hiding others. The way employees manage the display of normatively appropriate behavior has been shown to be associated with service performance and organizational effectiveness (e.g., Chi, Grandey, Diamond, \& Krimmel, 2011; Totterdell \& Holman, 2003). Service workers who are particularly required to follow organizational display rules by showing positive emotions can engage in surface acting (Grandey, 2000; Gross, 1998) by suppressing, amplifying, or faking emotions, or they can engage in deep acting (Grandey, 2000; Gross, 1998) by changing the situation or the perception of the situation. Surface acting has been shown to be detrimental for employees' well-being and job attitudes (Hülsheger \& Schewe, 2011). Experiencing emotional dissonance (Grandey, 2000; Hochschild, 1983; Zapf, Vogt, Seifert, Mertini, \& Isic, 1999)—the mismatch between 
felt emotion and organizationally desired expressions of emotions- has been found to be harmful for employees' well-being (Zapf, 2002). Emotional dissonance should be of special importance in the service sector.

Although researchers have acknowledged social conflicts as key work stressors (e.g., Bolger et al., 1989; Hashimoto, 1995; Spector \& Bruk-Lee, 2008; Thomas et al., 2005), more research is needed: First, scant attention has been paid to the short-term effects of social conflicts over a working day (for exceptions, see, e.g., Bolger et al., 1989; Ilies et al., 2011). Second and most important, research that goes beyond the detrimental effects of social conflict at work by investigating their relationships with employees' nonwork experiences is nearly nonexistent, but it is important to evaluate how far reaching and detrimental workplace conflicts actually are.

This study makes at least three contributions: First, our study goes beyond existing research by investigating daily spillover effects from SCCs to nonwork experiences. Spillover describes "effects of work and family on one another that generate similarities between these domains" (Edwards \& Rothbard, 2000, p. 180). If SCCs are detrimental even beyond the work time, organizations and individuals would have to consider steps to prevent the immediate effects of customer conflicts or, if not possible, help employees to deal with this uncontrollable and dysfunctional work stressor (e.g., by training employees in healthy emotion regulation strategies).

Second, our study goes beyond existing research by investigating immediate effects of customer conflicts on nonwork experiences. Existing research either has examined other sources of conflicts, such as supervisor or coworker conflict (Ilies et al., 2011), or used broader categories of workplace conflicts (Bolger et al., 1989; Mroczek \& Almeida, 2004). Moreover, when customer conflicts have been studied (Sliter et al., 2011; Totterdell \& Holman, 2003; Tschan, Rochat, \& Zapf, 2005), the development of SCCs over a working day and consequences for employees' private lives on a daily basis have not been considered. Customer conflicts are important to consider because negative and angerprovoking events are often associated with customer interactions. For example, Grandey, Dickter, and Sin (2004) found in a diary study that $43 \%$ of the anger-provoking events were associated with customer interactions. In comparison with conflict from coworkers, customer conflict has been shown to have even worse consequences (Sliter et al., 2011). Workplace conflicts with customers can be regarded as a central source of stress at work because employees in the service sector spend a large amount of time with customers and also often have to deal with a large number of different customers per day (Dormann \& Zapf, 2004).

Third, the goal of the study was to broaden our understanding of explanatory factors for potential spillover effects from the work to the nonwork domain. Specifically, we suggest that negative affect (NA), as an indicator of impaired well-being, acts as a mediator in the SCC-nonwork relationship. Knowledge about mediating processes will help design practical interventions for reducing detrimental effects of workplace conflicts.

\section{Theoretical Background and Development of Hypotheses}

On a general level, workplace conflicts can be defined as "a process that begins when an individual or group perceives differences and opposition between him- or herself and another individ- ual or group about interests, beliefs, or values that matter to him or her" (De Dreu \& Beersma, 2005, p. 106).

SCCs share some aspects with related concepts such as workplace aggression (R. A. Baron \& Neumann, 1996; Hershcovis et al., 2007) and incivility (Andersson \& Pearson, 1999; Cortina \& Magley, 2009; Cortina, Magley, Hunter Williams, \& Langhout, 2001), but there are also important differences. In line with other authors (e.g., Dormann \& Zapf, 2004; Grandey et al., 2004), we consider direct forms of aggression (e.g., physical aggression) to be less relevant in the customer interaction but the less direct forms of workplace aggression (e.g., yelling at the service provider) are also meaningful in the employee-customer interaction. Incivility (e.g., showing disrespect, degradation) as a mild and less intentional form of deviant work behavior (e.g., Cortina et al., 2001) focuses in comparison with SCCs primarily on stressful actions from "insiders" (e.g., supervisors) than "outsiders" (e.g., customers; Cortina et al., 2001). However, all three constructs share the potential threat for employees' self-esteem.

We expected that there would be an association between customer conflicts at work and nonwork experiences, mediated by $\mathrm{NA}$, as an indicator of impaired well-being. We examined two nonwork experiences: psychological detachment from work and negative work reflection. By examining psychological detachment and negative work reflection, we were able to study both resourceproviding and resource-depleting nonwork experiences. We define resource-providing experiences as afterwork activities that replenish psychological, cognitive, social, and physical resources. In contrast, resource-depleting experiences refer to activities that are effort consuming and drainful, thus further depleting employees' resources (cf. Fritz \& Sonnentag, 2006).

Psychological detachment from work has been defined by Etzion, Eden, and Lapidot (1998) as "the individual sense of being away from the work situation" (p. 579). It implies the absence of work-related thoughts. Being mentally detached from work helps individuals to recover from stress and benefits well-being and (at a medium level) job performance (e.g., Fritz, Yankelevich, Zarubin, \& Barger, 2010; Sonnentag, Binnewies, \& Mojza, 2008). In contrast, negative work reflection refers to thinking about the negative aspects of one's workday, such as failures and unpleasant customer interactions (cf. Binnewies, Sonnentag, \& Mojza, 2009a; Fritz \& Sonnentag, 2006). Negative work reflection is thought to be effort consuming and exhausting because employees in their leisure time are still mentally confronted with work demands. Negative work reflection has detrimental consequences, particularly for employees' well-being (Fritz \& Sonnentag, 2006).

\section{Social Conflicts With Customers at Work and Nonwork Experiences}

Employees can be affected by negative work events directly after exposure to them, but it is important to note that these events can exert their negative influences on employees by impairing recovery processes even a significant time afterward (e.g., after returning home). Insufficient psychological detachment from work (e.g., by thinking about work-related issues while at home; Sonnentag \& Bayer, 2005) and rumination processes (Martin \& Tesser, 1996) in terms of thinking about the negative aspects of work are likely to occur on days when an employee has been exposed to SCCs. 
In the following, we develop our hypotheses regarding SCCs and nonwork experiences and our postulated mediator of NA in the SCC-nonwork relationship.

\section{Social Conflicts With Customers at Work and Psychological Detachment}

One of the most central aspects of recovery processes is psychological detachment from work (Etzion et al., 1998; Sonnentag $\&$ Bayer, 2005). Recovery from work demands requires not only being physically away from the workplace but also mentally "switching" off from work. Job-related thoughts and job-related activities should be absent after work. Therefore, to refrain from job demands, employees are advised to take a mental break from work-related issues.

Psychological detachment from work has been demonstrated to be important for numerous work- and non-work-related outcomes. For example, one study with 527 Finnish employees showed that psychological detachment was directly related to occupational well-being and also functioned as a moderator in the relationship between psychosocial work characteristics and occupational wellbeing (Siltaloppi, Kinnunen, \& Feldt, 2009). In a recent study, Fritz et al. (2010) showed that mentally distancing oneself from work was positively related to life satisfaction and negatively related to emotional exhaustion.

Research indicates that several job situation variables, such as time pressure and workload, are negatively related to psychological detachment from work (Siltaloppi et al., 2009; Sonnentag \& Kruel, 2006). SCCs as one of the most severe work stressors are very likely to impair employees' psychological detachment from work. When employees are confronted with customers who show disproportionate behavior, they might, for instance, experience an imbalance between their input (e.g., showing attention and respect toward the customer) and subsequent output (e.g., unfriendly and insulting customer behavior) necessary for equity perceptions (Adams, 1965), or they might experience this behavior as an offense to the self (De Cremer, 2002; Semmer, Jacobshagen, Meier, \& Elfering, 2007). Even when not being actively concerned with workrelated tasks that could impair psychological detachment from work, employees might anticipate what they have to do on the next workday and they probably fear future customer conflicts (Mueller \& Tschan, 2011). Awareness that not all customer problems have been solved during the workday also might make it difficult to detach from work.

Taken together, we proposed the following:

Hypothesis 1: Conflicts with customers at work will be negatively related to psychological detachment from work during evening hours.

\section{Social Conflicts With Customers at Work and Negative Work Reflection}

Besides the importance of psychological detachment from work for recovery, we suggest that SCCs are related to employees' negative work reflection. Negative work reflection means that one thinks about the negative aspects of work and that one considers what one does not like about one's job. In contrast to psychological detachment from work, negative work reflection refers to the fact that one still thinks of negative work aspects and has unintentional preservative thoughts (Nolen-Hoeksema \& Morrow, 1993). Negative work reflection is effort consuming, leads to prolonged activation, and produces a feeling of helplessness (Binnewies, Sonnentag, \& Mojza, 2009b; Cropley \& Purvis, 2003).

Empirical findings indicate that negative work reflection has detrimental costs with respect to health and well-being (Fritz \& Sonnentag, 2006). Research from social cognition literature helps to better understand why SCCs should be related to negative work reflection. Martin and Tesser (1996) defined rumination as "a class of conscious thoughts that revolve around a common instrumental theme and that recur in the absence of immediate environmental demands requiring the thoughts" (p. 7). Rumination occurs when people are not able to attain a self-referent goal, with detrimental effects for employees' well-being and self-esteem (Martin \& Tesser, 1996).

In line with rumination theory (Martin \& Tesser, 1996, 2006), we argue that a high level of daily SCCs is related to increased negative work reflection because employees are not able to achieve a desired outcome with the customer. Instead, goal pursuit is interrupted, leading to negative work-related thoughts after a negative customer interaction. Imagine, for example, a customer service employee who is confronted with a customer who has disproportionate expectations and the customer service employee is not able to achieve a satisfactory solution because she is not able to deviate from a prescribed working procedure. From a control theoretical perspective (Carver \& Scheier, 1990; Watkins, 2008), the customer conflict reflects negative feedback concerning goalrelevant behavior. The lack of goal fulfillment makes the employee susceptible to rumination. Moreover, after a negative customer interaction, the situation cannot be changed.

Taken together, we proposed the following:

Hypothesis 2: Conflicts with customers at work will be positively related to negative work reflection during evening hours.

\section{The Mediating Role of Negative Affect in the Relationship Between Social Conflicts With Customers and Nonwork Experiences}

Building on affective events theory (Weiss \& Cropanzano, 1996) as well as empirical findings, we proposed that NA would act as a mediator in the relationship between SCCs and nonwork experiences (i.e., psychological detachment from work and negative work reflection). Studies using a within-person design have shown that social conflicts contribute to daily variations in NA (e.g., Bolger et al., 1989; Ilies et al., 2011). Moreover, previous research has shown that daily variations in NA impair employees' well-being (e.g., Judge, Woolf, \& Hurst, 2009; Merz \& Roesch, 2010).

We argue that daily variations in NA should also influence employees' nonwork experiences. On the basis of the mood-asinformation model (Schwarz, 1990), we suggest that NA is negatively related to psychological detachment from work and positively related to negative work reflection. The mood-asinformation model basically suggests that people in a positive mood engage in heuristic information processing because they use their positive mood as a signal that they are on the "right track" and that the environment is secure. On the contrary, people in a 
negative mood engage in careful and resource-consuming information processes because their negative mood indicates that they should adjust their behavior in order to resolve problematic issues and that they should allocate their attention to details. Empirical studies have found effects of mood on various outcomes, such as information processing, attributions, and judgments of well-being (Bless, Mackie, \& Schwarz, 1992; Schwarz \& Clore, 1983). People also spend more time reasoning about negative experiences compared with positive experiences (Abele, 1985).

Translated to our research question of the NA-nonwork experiences relationship, we argue that NA should lead employees to allocate more attention to the customer conflict, also when at home, in order to find ways to adjust their behavior and to resolve the unpleasant situation. As people's long-term memory is influenced by the affective states when they encode the respective information (Bower, 1981; Buchanan, 2007), NA should increase the likelihood of people's retrieval of negative work events when at home (i.e., conflicts at work). Therefore, people will be less able to mentally refrain from work (i.e., psychologically detach from work) because they might engage in work-related thinking during their leisure time. Moreover, not only will their psychological detachment from work be decreased as they engage in workrelated thoughts instead of leisure-related activities, but they will also focus on the negative aspects of their work during leisure time (i.e., negative work reflection).

Taken together, we proposed that NA would mediate the relationships between SCCs and nonwork experiences.

Hypothesis 3: State NA mediates the relationship between conflicts with customers at work and psychological detachment from work.

Hypothesis 4: State NA mediates the relationship between conflicts with customers at work and negative work reflection.

\section{Method}

\section{Overview}

We used a within-person design and conducted an experiencesampling study with 98 employees from civil service agencies in Germany. Data were collected by a general survey and by daily surveys. Participants filled in daily surveys over 5 consecutive workdays (Monday-Friday), two times per day (i.e., at the end of the workday, after the workday). The general survey was completed 1 week before the start of the daily surveys. We collected data on SCCs and well-being (i.e., NA) at the end of the workday and measures of nonwork experiences (i.e., detachment and negative work reflection) at bedtime.

\section{Procedure and Sample}

We approached managers of civil service agencies in the south of Germany, described the aim of the study, and asked for permission to recruit participants. We introduced our study as research on "work and well-being." On managers' agreement, we sent information about the study's goals and content to employees via Intranet or e-mail systems. Participants could send an e-mail or fax to the research team, indicating their interest to participate in the study. After registration, participants received a survey package with detailed instructions on when and how to fill out questionnaires. Participants had to write down the exact time when they completed each questionnaire. We emphasized confidentiality and the fact that the study was conducted in agreement-but independent of - the organization. To match questionnaires while assuring confidentiality, participants were asked to indicate a code on each questionnaire. Completed questionnaires were sent back to the research team in a prestamped envelope. As an incentive, we offered participation in a lottery and detailed feedback on the results after study completion.

Overall, 138 employees from 18 civil service agencies agreed to participate in our study. From these, 101 sent back questionnaires to our research team, resulting in a response rate of $73.19 \%$. We checked whether participants filled out the surveys during the requested time frames (i.e., at the end of the workday, at bedtime). As a consequence, three participants were excluded from analyses because of noncompliance with study instructions (i.e., they did not fill in the questionnaires at the requested time), resulting in a final sample of 98 participants. The number of surveys completed at the end of the workday ranged between 446 and 460, and between 479 and 482 surveys were completed at bedtime. All participants had customer contact on a frequent, daily basis. The core task duty of the participants in their jobs was to interact with and consult customers who had, for example, inquiries regarding youth welfare office issues or requests for unemployment compensation.

Participants (67.3\% were women) had an average age of 39.78 years $(S D=10.76)$, ranging from 20 to 60 years. Most participants held a university degree or a comparable education (48.0\%), followed by participants with an apprenticeship (35.7\%) or with a master craftsman (16.3\%). Overall, $29.6 \%$ of the participants held a supervisory position. Participants had, on average, 15.2 years of job experience $(S D=10.59)$ and had worked in the current company for 11.30 years $(S D=9.34)$ on average. With respect to the living and family situation, the majority of participants reported living with a partner $(63.2 \%)$, followed by participants who reported living alone $(30.7 \%)$. The other participants $(6.1 \%)$ indicated living with another person (e.g., sibling, parents). Overall, $38.8 \%$ of participants indicated having children. Participants had, on average, $39.63 \mathrm{hr}(S D=2.75)$ weekly contract working hours.

\section{Measures}

Following the procedure from other research using daily surveys (e.g., Ilies et al., 2011; Judge et al., 2009), we slightly rephrased items to suit the format of daily assessment. All items were in German. Scales developed in English were translated into German by the first author and back-translated to English by native speakers.

Social conflicts at work with customers. We measured SCCs daily, at the end of the workday, with the 16-item customerrelated social stressor scale by Dormann and Zapf (2004; cf. also Dudenhöffer \& Dormann, 2010). Participants were instructed to indicate for the respective afternoon on 5-point Likert scales $(1=$ not at all true to $5=$ totally true) how much the following items were true. Sample items included "This afternoon, I had to deal with customers/clients who did not understand that we have to comply with some rules," "This afternoon, I had to deal with 
citizens/clients who criticized me," and "This afternoon, I had to deal with some unfriendly customers." Cronbach's alphas ranged from .91 to .94 over the 5 days (mean $\alpha=.93$ ).

Psychological detachment from work. We measured psychological detachment from work in the bedtime questionnaire with the four-item scale developed by Sonnentag and Fritz (2007). A sample item included "Today I forgot about work during afterwork hours." Participants were instructed to report their day-level evaluation of psychological detachment from work (as opposed to their general level of detachment) on 5-point Likert scales $(1=$ fully disagree to $5=$ fully agree; Sonnentag et al., 2008). Cronbach's alphas ranged from .90 to .94 over the 5 days (mean $\alpha=.92$ ).

Negative work reflection. We measured negative work reflection in the bedtime questionnaire with four items from Binnewies et al. (2009b). A sample item included "Today, during leisure time I realized what it is that I do not like about my work." Again, participants were instructed to report their day-level evaluation of negative work reflection after work on that specific day (as opposed to their general level of negative work reflection) on 5 -point Likert scales ( $1=$ fully disagree to $5=$ fully agree $)$. Cronbach's alphas ranged from .94 to .95 over the 5 days (mean $\alpha=.95)$.

To show that the constructs psychological detachment from work and negative work reflection were empirically distinct, we conducted a series of confirmatory factor analyses. In a two-factor model, we modeled two correlated latent factors (psychological detachment and negative work reflection). Every item that was supposed to measure each construct was allowed to load on the corresponding latent factor (i.e., all psychological detachment items on the latent psychological detachment factor, and the negative work reflection on the latent negative work reflection factor). This model should have the best model fit, evaluated by a $\chi^{2}$ difference test, compared with alternative models with fewer latent factors (cf. Kline, 2005). We compared the two-factor model with an alternative one-factor model (all items of all scales were allowed to load on one latent factor) for the 5 consecutive days, separately. The two-factor model showed an acceptable fit for all 5 days (Day 1: $\chi^{2}=35.12, d f=17$; comparative fit index $[\mathrm{CFI}]=0.98$; Tucker-Lewis index $[\mathrm{TLI}]=0.96$; root mean square error of approximation $[\mathrm{RMSEA}]=0.10$; standardized root mean residual $[\mathrm{SRMR}]=0.03$; Day $2: \chi^{2}=41.44, d f=17$; $\mathrm{CFI}=0.97$; TLI $=0.95$; RMSEA $=0.12$; SRMR $=0.03$; Day 3 : $\chi^{2}=27.49, d f=17$ CFI $=0.99 ;$ TLI $=0.98 ;$ RMSEA $=0.08 ;$ SRMR $=0.04$; Day $4: \chi^{2}=27.74, d f=17$; CFI $=0.99$; TLI $=$ 0.98 ; RMSEA $=0.08 ;$ SRMR $=0.03$; Day $5: \chi^{2}=20.11, d f=17$; $\mathrm{CFI}=1.00 ; \mathrm{TLI}=0.99 ; \mathrm{RMSEA}=0.04 ; \mathrm{SRMR}=0.03)$ and fit the data better than a one-factor model $\left(\Delta \chi^{2}\right.$ ranging between 104.33 and $212.56, \Delta d f=1, p s<.001)$. In summary, we concluded that these measures represent empirically distinct constructs.

Negative affect. Following the procedure from Sonnentag et al. (2008), we assessed NA daily at the end of the workday with six items of the Positive and Negative Affect Scale (Watson, Clark, \& Tellegen, 1988). Participants indicated on 5-point Likert scales $(1=$ not at all to $5=$ very $m u c h)$ the degree to which they felt "at this moment" each affective state described by the adjectives (e.g., nervous, distressed, scared). Cronbach's alphas ranged from .77 to .84 over the 5 days (mean $\alpha=.80$ ).
Control variables. We controlled for age, gender $(1=$ women, 2 = men), leadership position (one item asking if the respondent had supervisory responsibilities: $1=$ no, $2=$ yes), and weekly working hours, as each of these variables has been found to relate to well-being and recovery experiences (e.g., Ilies et al., 2007; Song, Foo, \& Uy, 2008). We assessed the control variables in the general survey.

\section{Results}

We analyzed our data with a multilevel random coefficient model using hierarchical linear modeling (HLM Version 6; Raudenbush, Bryk, Cheong, \& Congdon, 2004). Days (Level 1) were nested within persons (Level 2). Level 2 data were centered around the grand mean and Level 1 data were centered around the respective person mean. Before testing our hypotheses, we had to test whether HLM was appropriate. Therefore, we ran null models to examine the between-persons and within-person variance components of the variables (i.e., SCCs, psychological detachment, negative work reflection, NA). For SCCs, within-individual variance was $60.59 \%$ (Level 1 intercept variance, i.e., 0.1494, divided by total variance, i.e., $0.1494+0.2297)$. For psychological detachment, negative work reflection, and NA, within-individual variances were $49.50 \%, 49.96 \%$, and $44.71 \%$, respectively. Accordingly, inspection of between-persons and within-person variance showed that a high proportion of the variance could be attributed to variance within persons, indicating that HLM was appropriate.

To test our hypotheses, we used the restricted maximum likelihood procedure in HLM (see Hox, 2002). For directional hypotheses, one-tailed tests are appropriate and are indicated as such. In addition, to confirm our mediation hypotheses, the coefficients of the mediator (i.e., NA) had to be significant after entering the independent variable (i.e., SCCs). Moreover, we estimated with 1,000 bootstrapping resamples the $99 \%$ confidence intervals for the indirect effects (Preacher \& Hayes, 2004) using Mplus (Muthén \& Muthén, 1998-2004). Means and standard deviations of all variables included in our analysis and zero-order correlations of variables at the person level and the mean values of the daylevel correlations are shown in Table 1.

\section{Social Conflicts With Customers at Work and Nonwork Experiences}

Psychological detachment from work. In Hypothesis 1, we predicted that day-level SCCs would be negatively related to psychological detachment at home. Results are shown in Table 2.

In the null model, the intercept was the only predictor. In Model 1 , we added the control variables (i.e., age, gender, leadership position, and weekly working hours). Analyses showed that Model 1 , in which the control variables were entered, did not show an improvement over the null model $(\Delta-2 \times \log =5.55, n s)$. Model 2a, which also included SCCs, showed significant improvement over Model $1(\Delta-2 \times \log =92.37, p<.001)$. Analyses indicated that day-level SCCs are significantly negatively related to psychological detachment from work during evening hours, $\gamma=$ $-0.1828, S E=0.1005, t=-1.82, p<.05$ (one-tailed). Thus, we found support for Hypothesis 1. 
Table 1

Means and Standard Deviations of Variables in the Multilevel Model and Correlations Among Person-Level Variables

\begin{tabular}{|c|c|c|c|c|c|c|c|c|c|c|}
\hline Variable & $M$ & $S D$ & 1 & 2 & 3 & 4 & 5 & 6 & 7 & 8 \\
\hline \multicolumn{11}{|l|}{ Person-level measures ${ }^{\mathrm{a}}$} \\
\hline 1. Age & 39.78 & 10.76 & - & .19 & $.38^{* * *}$ & -.05 & & & & \\
\hline 2. Gender ${ }^{\mathrm{b}}$ & 1.33 & 0.47 & & - & $.23^{*}$ & $.31^{* *}$ & & & & \\
\hline 3. Leadership position ${ }^{\mathrm{c}}$ & 1.30 & 0.46 & & & - & $.25^{*}$ & & & & \\
\hline 4. Working hours & 39.63 & 2.75 & & & & - & & & & \\
\hline \multicolumn{11}{|l|}{ Daily measures ${ }^{\mathrm{d}}$} \\
\hline 5. SCCs & 1.51 & 0.62 & & & & & - & $37^{* * *}$ & $.19^{* *}$ & $.26^{* * *}$ \\
\hline 6. NA & 1.41 & 0.58 & & & & & & - & $-.34^{* *}$ & $.39^{\text {** }}$ \\
\hline 7. Psychological detachment from work & 3.52 & 1.09 & & & & & & & - & $-.56^{* * *}$ \\
\hline 8. Negative work reflection & 1.92 & 1.06 & & & & & & & & - \\
\hline
\end{tabular}

Note. $\quad$ SCCs $=$ social conflicts with customers at work; NA $=$ negative affect.

${ }^{\mathrm{a}} N=98 .{ }^{\mathrm{b}}$ Gender is coded as $1=$ female, $2=$ male. ${ }^{\mathrm{c}}$ Leadership position is coded as $1=$ no, $2=$ yes. ${ }^{\mathrm{d}} n=446-482$.

${ }^{*} p<.05 . \quad{ }^{* *} p<.01$.

Negative work reflection. In Hypothesis 2, we predicted that day-level SCCs would be positively related to negative work reflection at home. Results are shown in Table 3.

Analyses showed that Model 1, in which the controls were entered, did not show an improvement over the null model $(\Delta-2 \times$ $\log =1.89, n s)$. Model 2a, which also included SCCs, showed significant improvement over Model $1(\Delta-2 \times \log =65.52, p<$ $.001)$. Analyses indicated that day-level SCCs are significantly positively related with negative work reflection during evening hours, $\gamma=0.2270, S E=0.1264, t=1.80, p<.05$ (one-tailed). We found support for Hypothesis 2.

The mediating role of NA in the SCCs-recovery experiences relationship. In Hypotheses 3 and 4, we predicted that NA would mediate the relationship between SCCs and psychological detachment from work and negative work reflection. According to R. M. Baron and Kenny (1986), four requirements have to be met: (a) a relationship between SCCs and psychological detachment from work (or negative work reflection), (b) a relationship between SCCs and NA, (c) a relationship between NA and psychological detachment from work (or negative work reflection), (d) a significantly decreased relationship between SCCs and psychological detachment from work (or negative work reflection) when NA is controlled for.

For psychological detachment from work, Step 1 was already supported when testing Hypothesis 1 showing that SCCs were negatively related to psychological detachment from work (see Table 2). Step 2 was also supported because the analysis showed a positive relationship between SCCs and NA (see Table 4), $\gamma=$ $0.1170, S E=0.0703, t=1.66, p<.05$ (one-tailed).

Step 3 was supported because we found a relationship between NA and psychological detachment from work (see Table 2 ). Specifically, we found that higher levels of NA were associated with lower levels of psychological detachment from work, $\gamma=-0.3682, S E=0.1023, t=-3.60, p<.01$. Step 4 was tested with an additional HLM regression analysis (see Table 5, Model 1a).

In Model 1a, we entered both the predictor (i.e., SCCs) and the mediator (i.e., NA) simultaneously to predict psychological detachment from work. Findings revealed that the relationship between SCCs and psychological detachment from work was no longer significant, $\gamma=-0.1417, S E=0.1032, t=-1.37$, $n s$, but the mediator NA was still significant, $\gamma=-0.3034, S E=0.1098$, $t=-2.77, p<.01$.

In addition, we applied the Monte Carlo method for testing the confidence intervals of the indirect effect using Mplus (Muthén \& Muthén, 1998-2004). The estimated 99\% confidence intervals for the indirect effect of SCCs via NA ranged from - 169 at the lower limit to -.032 at the upper limit, indicating a significant indirect effect. Taken together, findings provide support for Hypothesis 3.

Our procedure for testing Hypothesis 4, in which we predicted that NA would mediate the relationship between SCCs and negative work reflection, was analogous to our procedure for testing Hypothesis 3. For negative work reflection, Step 1 was already supported when analyzing Hypothesis 2, as SCCs were related to negative work reflection at bedtime (see Table 3). Step 2 was supported because findings showed a positive relationship between SCCs and NA (see Table 4). Step 3 was supported because we found a relationship between NA and negative work reflection. Specifically, a high level of NA was associated with higher levels of negative work reflection, $\gamma=0.2299, S E=0.0895, t=2.57$, $p<.05$ (see Table 3). Step 4 was tested with an additional HLM regression analyses (see Table 5). In Model 1b, we entered both the predictor (i.e., SCCs) and the mediator (i.e., NA) simultaneously to predict negative work reflection. Findings revealed that the relationship between SCCs and negative work reflection was no longer significant, $\gamma=0.1917, S E=0.1249, t=1.54, n s$, but the mediator NA was still significant, $\gamma=0.1970, S E=0.0850$, $t=2.32, p<.05$. Again, for bootstrapping, we used 1,000 resamples to estimate the $99 \%$ confidence intervals for the indirect effect. The estimated $99 \%$ confidence intervals for the indirect effect of SCCs via NA ranged from .045 at the lower limit to .212 at the upper limit, indicating a significant indirect effect. The SCC-negative work relationship was mediated by NA. Taken together, analyses provide support for Hypothesis 4 .

\section{Additional Analyses}

In response to reviewers' comments, we tested models in which we added positive affect (PA) to see whether it is a lack of PA (rather than higher levels of NA) that accounts for the effects of 




SCCs on nonwork variables. ${ }^{1}$ Results showed that PA did not turn out to be relevant in the SCC-nonwork relationship. Therefore, it seems that SCCs are associated with higher levels of NA, not with reduced PA. Moreover, we ran analyses in which we controlled for serial dependency (i.e., autocorrelation). We controlled for the lag of the dependent variable and found that results did not change substantially. ${ }^{2}$

\section{Discussion}

Given the vital role of service in today's work environment, the goal of our study was to contribute to the understanding of the daily effects of negative customer interactions by examining how SCCs relate to employees' well-being and nonwork outcomes. We proposed that SCCs are goal-disrupting and resource-depleting experiences; thus, they are negatively related to psychological detachment and positively related to negative work reflection. Furthermore, following affective events theory (Weiss \& Cropanzano, 1996), we proposed that state NA would mediate the SCCnonwork relationship. The results of our study support these propositions.

Specifically, we found a negative relationship between daily SCCs and psychological detachment from work. On days with more experience of SCCs, employees found it more difficult to "switch off mentally" from work. Likewise, we found a positive relationship between daily SCCs and negative work reflection. On days when employees indicated more experience of negative customer-related interactions, they continued to think about the negative aspects of work during evening hours. In addition, we showed that NA mediates the relationship between SCCs and nonwork experiences. Thus, SCCs affect resource-providing and resource-depleting nonwork experiences.

To our knowledge, our study is the first to examine the association of SCCs with nonwork experiences, and we conducted it on a daily level. Knowing about the association of SCCs with nonwork outcomes on a daily level is important because it shows that people's well-being is not only reduced by negative work events (here, customer conflicts) directly after exposure to them, but that employees' nonwork experiences are also impaired. Our findings demonstrate that people are less able to detach from work, which would be important to restoring resources to cope with upcoming demands. In addition, in line with social cognition research on rumination (Martin \& Tesser, 1996, 2006), our findings suggest that employees who experience SCCs cannot easily stop recurring thoughts that revolve around work-related issues that have passed. Obviously, SCCs can trigger downward developmental spirals, which should be interrupted immediately to prevent any negative outcomes. As we outlined in the introduction, customer conflicts are different from other workplace conflicts (e.g., supervisor conflict, coworker conflict), with severe con-

\footnotetext{
${ }^{1}$ Following a procedure from Sonnentag et al. (2008), we assessed PA with six items from the Positive and Negative Affect Schedule (Watson et al., 1988). Participants indicated on 5-point Likert scales $(1=$ not at all to $5=$ very much) the degree to which they felt "at this moment" each affective state described by the adjectives (e.g., active, interested, excited). Cronbach's alphas ranged from .85 to .88 over the 5 days (mean $\alpha=.86$ ).

${ }^{2}$ Detailed analyses can be obtained from the first author.
} 
Table 3

Multilevel Estimates for Models Predicting Day-Specific Negative Work Reflection Reported at Bedtime

\begin{tabular}{|c|c|c|c|c|c|c|c|c|c|c|c|c|}
\hline \multirow[b]{2}{*}{ Variable } & \multicolumn{3}{|c|}{ Null model } & \multicolumn{3}{|c|}{ Model 1} & \multicolumn{3}{|c|}{ Model 2a } & \multicolumn{3}{|c|}{ Model 2b } \\
\hline & Estimate & $S E$ & $t$ & Estimate & $S E$ & $t$ & Estimate & $S E$ & $t$ & Estimate & $S E$ & $t$ \\
\hline Intercept & 1.9168 & 0.0832 & $23.05^{* *}$ & 1.9174 & 0.0823 & $23.29^{* * * *}$ & 1.9250 & 0.0828 & $23.26^{* *}$ & 1.9147 & 0.0823 & $23.28^{* * * *}$ \\
\hline Age & & & & -0.0042 & 0.0075 & -0.55 & -0.0073 & 0.0074 & -0.99 & -0.0065 & 0.0072 & -0.91 \\
\hline Gender $^{\mathrm{a}}$ & & & & -0.0814 & 0.2104 & -0.39 & -0.0964 & 0.2118 & -0.46 & -0.0695 & 0.2123 & -0.33 \\
\hline Leadership position ${ }^{\mathrm{b}}$ & & & & -0.0740 & 0.2160 & -0.34 & -0.0437 & 0.2152 & -0.20 & -0.0622 & 0.2147 & -0.29 \\
\hline Working hours & & & & 0.0115 & 0.0069 & $1.68^{\dagger}$ & 0.0115 & 0.0065 & $1.76^{\dagger}$ & 0.0111 & 0.0068 & 1.64 \\
\hline $\mathrm{SCCs}$ & & & & & & & 0.2270 & 0.1264 & $1.80^{\dagger}$ & & & \\
\hline NA & & & & & & & & & & 0.2299 & 0.0895 & $2.57^{*}$ \\
\hline$\Delta$ Deviance & & & & & 1.89 & & & $65.52^{* * * * *}$ & & & $35.73^{* * * \mathrm{c}}$ & \\
\hline Level 1 intercept & & 0.5618 & & & 0.5618 & & & 0.5428 & & & 0.5555 & \\
\hline Level 2 intercept & & 0.5610 & & & 0.5476 & & & 0.5410 & & & 0.5765 & \\
\hline
\end{tabular}

Note. $\quad$ SCCs $=$ social conflicts with customers at work; NA $=$ negative affect.

${ }^{\mathrm{a}}$ Gender is coded as $1=$ female, $2=$ male. ${ }^{\mathrm{b}}$ Leadership position is coded as $1=$ no, $2=$ yes. ${ }^{\mathrm{c}}$ Deviance comparison with Model 1 .

${ }^{*} p<.05$. *** $p<.01$

sequences because there is often no opportunity to resolve the conflict afterward (cf. Sliter et al., 2011), which interrupts goal achievement and can be self-threatening (De Cremer, 2002; Semmer et al., 2007). Thus, it is important to pay special attention to customer conflicts.

\section{Implications for Research and Practice}

Our findings indicate that customer conflicts have the potential to be harmful for employees' well-being and nonwork experiences. Our study broadens conflict research by demonstrating that there are daily spillover effects from SCCs to nonwork experiences. Not being able to recover from work during leisure time in turn is associated with numerous negative consequences, such as psychosomatic and cardiovascular health problems, depression, and emotional exhaustion (e.g., de Bloom et al., 2010; Eden, 2001). Given the large number of employees working in the service sector, organizations need to consider steps to help employees deal with this uncontrollable and dysfunctional stressor.

For future research, the role of EL (Hochschild, 1983) would be important to consider. Deep acting has been considered to be the more effective strategy regarding effectiveness and individual well-being (e.g., Chi et al., 2011; Grandey et al., 2004; Hülsheger $\&$ Schewe, 2011). Deep acting, which induces the desired feelings in oneself by imaging a prior event or by reappraising the situation, should help diminish the negative consequences of unpleasant customer interactions. Deep acting enhances employees' mood and mobilizes employees' energy and social resources by positive customer reactions (cf., e.g., Brotheridge \& Lee, 2002; Côté, 2005). Dormann and Zapf (2004) built the here-used SCC scale on the grounding of Hochschild's (1983) concept of EL. They have shown that SCCs and emotional dissonance-as the key variable of EL-are distinct constructs and show different patterns with burnout dimensions. In customer interactions, emotional dissonance can occur but does not cover all aspects of negative service provider-customer interactions (cf. Zapf \& Dormann, 2004). For example, a service provider may be allowed to express negative emotions (e.g., teachers). Future research endeavors may aim at investigating processes and causal pathways of EL in the SCCnonwork experiences relationship (Grandey et al., 2004; Rupp \& Spencer, 2006).

Table 4

Multilevel Estimates for Models Predicting Day-Specific Negative Affect

\begin{tabular}{|c|c|c|c|c|c|c|c|c|c|}
\hline \multirow[b]{2}{*}{ Variable } & \multicolumn{3}{|c|}{ Null model } & \multicolumn{3}{|c|}{ Model 1} & \multicolumn{3}{|c|}{ Model 2} \\
\hline & Estimate & $S E$ & $t$ & Estimate & $S E$ & $t$ & Estimate & $S E$ & $t$ \\
\hline Intercept & 1.4102 & 0.0436 & $32.36^{* * *}$ & 1.4101 & 0.0429 & $32.90^{\text {**** }}$ & 1.4117 & 0.04357 & $32.40^{* * * *}$ \\
\hline Age & & & & -0.0012 & 0.0035 & -0.34 & -0.0016 & 0.0035 & -0.46 \\
\hline Gender ${ }^{\mathrm{a}}$ & & & & 0.0386 & 0.1244 & 0.31 & 0.0182 & 0.1174 & 0.16 \\
\hline Leadership position ${ }^{\mathrm{b}}$ & & & & -0.1477 & 0.1189 & -1.24 & -0.1763 & 0.1081 & -1.63 \\
\hline Working hours & & & & 0.0071 & 0.0038 & $1.86^{\dagger}$ & 0.0075 & 0.0035 & $2.15^{*}$ \\
\hline SCCs & & & & & & & 0.1170 & 0.0703 & $1.66^{\dagger}$ \\
\hline$\Delta$ Deviance & & & & & $20.05^{\text {**** }}$ & & & $29.78^{* * * * *}$ & \\
\hline Level 1 intercept variance & & 0.1817 & & & 0.1817 & & & 0.1645 & \\
\hline Level 2 intercept variance & & 0.1488 & & & 0.1505 & & & 0.1572 & \\
\hline
\end{tabular}

Note. $\mathrm{SCCs}=$ social conflicts with customers at work; $\mathrm{NA}=$ negative affect.

${ }^{\text {a }}$ Gender is coded as $1=$ female, $2=$ male. ${ }^{\mathrm{b}}$ Leadership position is coded as $1=$ no, $2=$ yes.

$* p<.05$. *** $p<.01$. 
Table 5

Multilevel Estimates for Models Testing the Mediating Role of Negative Affect (NA) in Relationship Between Social Conflicts at Work With Customers (SCCs) With Psychological Detachment From Work (Model 1a) and Negative Work Reflection (Model 1b) Reported at Bedtime

\begin{tabular}{|c|c|c|c|c|c|c|}
\hline \multirow[b]{2}{*}{ Variable } & \multicolumn{3}{|c|}{ Model 1a } & \multicolumn{3}{|c|}{ Model 1b } \\
\hline & Estimate & $S E$ & $t$ & Estimate & $S E$ & $t$ \\
\hline Intercept & 3.4923 & 0.0841 & $41.53^{* * * * *}$ & 1.9252 & 0.0827 & $23.27^{\text {***** }}$ \\
\hline Age & -.0079 & 0.0075 & -1.06 & -0.0079 & 0.0072 & -1.09 \\
\hline Gender $^{\mathrm{a}}$ & -.00454 & 0.2161 & -0.21 & -0.0833 & 0.2118 & -0.39 \\
\hline Leadership position $^{\mathrm{b}}$ & -0.0071 & 0.2402 & -0.03 & -0.0481 & 0.2136 & -0.23 \\
\hline Working hours & -0.0185 & 0.0082 & $-2.27^{*}$ & 0.0108 & 0.0068 & 1.59 \\
\hline NA & -0.3043 & 0.1098 & $-2.77^{* * *}$ & 0.1970 & 0.0850 & $2.32^{*}$ \\
\hline $\mathrm{SCCs}$ & -0.1417 & 0.1032 & -1.37 & 0.1917 & 0.1249 & 1.54 \\
\hline$\Delta$ Deviance & & $11.43^{* * * *}$ & & & $9.21^{* *}$ & \\
\hline Level 1 intercept & & 0.5686 & & & 0.5288 & \\
\hline Level 2 intercept & & 0.5621 & & & 0.5442 & \\
\hline
\end{tabular}

${ }^{\text {a }}$ Gender is coded as $1=$ female, $2=$ male. ${ }^{\text {b }}$ Leadership position is coded as $1=$ no, $2=$ yes.

${ }^{*} p<.05$. ${ }^{* *} p<.01$.

When it comes to practical implications, our study suggests that responsible organizations should be aware of the detrimental associations of difficult customer interactions, not only with employees' NA, but also with their private life experiences. It appears central to uplift employees' negative mood in order to put employees in the mode to recover from demanding work environments. According to the affective shift model (Bledow, Schmitt, Frese, \& Kühnel, 2011), helping individuals to put themselves in a positive mood can improve workplace outcomes. Positive self-instructions might help employees to put themselves in a better mood and to increase their self-esteem (Lange, Richard, Gest, de Vries, \& Lodder, 1998). Moreover, allowing employees to take breaks at work might be an effective intervention because it shifts power and control to employees and gives employees opportunities to recover from customer conflicts immediately (cf. Sliter et al., 2011). In addition, it might help to offer support from supervisors and coworkers (Giebels \& Janssen, 2005; Ilies et al., 2011). Experiencing others offering to help to deal with difficult customers and to share the problems should diminish the negative effects of SCCs on employees' well-being and beyond. Organizations could also provide service workers with training to learn deep-acting skills, such as situation reappraisal techniques, or teaching employees to focus on the positive aspects of a situation (Grandey \& Diamond, 2010). Adjusting organizational factors (e.g., offering autonomy, supervisor support) and considering individual differences (e.g., personality, emotional intelligence) in staffing decisions may also help service providers to interact with clients and customers in an effective way (Grandey, 2000; Grandey et al., 2004; Judge et al., 2009). For example, Grandey et al. (2004) found that service workers who felt threatened by verbal customer aggression used surface acting, whereas those who felt less threatened used deep acting. In addition, the authors showed that employees with a high level of job autonomy felt less threatened by customers. Therefore, although organizations are not able to curtail all customer conflicts, they have the power to design the work environment.

\section{Potential Limitations}

Our study is not without limitations. The first limitation refers to our data collection procedure. Although researchers conducting diaries studies also have used survey packages (e.g., Sanz-Vergel, Demerouti, Bakker, \& Moreno-Jiménez, 2011; Xanthopoulou, Bakker, Heuven, Demerouti, \& Schaufeli, 2008), future research should make use of electronic data collection procedures (e.g., handheld computers), which provide reliable information on when participants filled out the questionnaire (Tennen, Affleck, Coyne, Larsen, \& DeLongis, 2006). Green, Rafaeli, Bolger, Shrout, and Reis (2006) concluded that "compliance is much more an issue of study design and participant motivation than it is an issue of whether a diary is administered in paper-and-pencil form or electronically" (p. 102). The number of surveys completed after the workday ranged between 446 and 460 ; between 479 and 482 surveys were completed at bedtime. The compliance rate of the workday surveys was slightly smaller than the compliance rate of the bedtime surveys. The workday surveys included items on the experience of SCCs, which employees could - on very rare occasions-not fill in because they had not had customer interactions on that particular day.

Following Green et al. (2006), we used some strategies to motivate participants (e.g., regular contacts before and during data collection between our research team and participants, detailed feedback on study results), which resulted in compliance rates higher than those normally observed in daily surveys. Participants' hand-made time and date stamps also indicated high compliance with our instructions. In addition, it seems unlikely that our participants had filled out the daily questionnaires at one time. The data showed that there was considerable within-person variance across the days for SCCs $(60.59 \%)$, NA (44.71\%), negative work reflection (49.96\%), and psychological detachment from work $(49.50 \%)$. In sum, although objective verification data would have been better, it seems that our participants showed a high amount of compliance with the diary protocol. 
Second, our sample consisted of civil service agents in Germany, leaving open the extent to which our findings can be generalized to other populations and other national cultures. We chose civil service agents because these employees have to deal with customers frequently over a workday. Future research should replicate findings with participants from other professions and cultures.

Third, as nonwork experiences we considered psychological detachment from work and negative work reflection. This was done to capture both resource-providing and resource-consuming activities. Theoretically, psychological detachment from work and negative work reflection are different constructs: Psychological detachment from work means that one is able to "switch off" from work, whereas negative work reflection refers to an employee's focus on the negative aspects of one's work. Future research should expand our findings by analyzing other indicators of employees' afterwork experiences that do not correlate highly with each other like psychological detachment from work and negative work reflection do (although they can be separated theoretically and empirically as two distinct constructs), such as relaxation, mastery, and control.

\section{Summary and Conclusion}

Our diary study extends past research by showing that negative customer interactions impair employees' nonwork experiences, suggesting that social stressor outcomes are not limited to the workplace context. Stressful customer interactions are negatively related to resource-providing experiences at bedtime and positively related to resource-consuming experiences at bedtime. Our study further demonstrates that employees' higher NA is a link between negative customer interactions and employees' nonwork experiences. Most important, our study broadens the scope of existing workplace conflict research by aligning daily customer conflicts' effects on work outcomes with nonwork experiences. For future research, it would be particularly useful to investigate individual and organizational factors that buffer the negative effects of social conflicts to improve the working conditions of a growing number of service workers.

\section{References}

Abele, A. (1985). Thinking about thinking. Causal, evaluative and finalistic cognitions about social situations. European Journal of Social Psychology, 15, 315-332. doi:10.1002/ejsp.2420150306

Adams, J. S. (1965). Inequity in social exchange. In L. Berkowitz (Ed.), Advances in experimental social psychology (Vol. 2, pp. 267-299). New York, NY: Academic Press.

Andersson, L. M., \& Pearson, C. M. (1999). Tit for tat? The spiraling effect of incivility in the workplace. Academy of Management Review, 24, 425-471.

Baron, R. A., \& Neumann, J. H. (1996). Workplace violence and workplace aggression: Evidence on their relative frequency and potential causes. Aggressive Behavior, 22, 161-173. doi:10.1002/(SICI)10982337(1996)22:3<161::AID-AB1>3.0.CO;2-Q

Baron, R. M., \& Kenny, D. A. (1986). The moderator-mediator variable distinction in social psychological research. Conceptual, strategic, and statistical considerations. Journal of Personality and Social Psychology, 51, 1173-1182. doi:10.1037/0022-3514.51.6.1173

Binnewies, C., Sonnentag, S., \& Mojza, E. J. (2009a). Daily performance at work: Feeling recovered in the morning as a predictor of day-level job performance. Journal of Organizational Behavior, 30, 67-93. doi: $10.1002 /$ job.541

Binnewies, C., Sonnentag, S., \& Mojza, E. J. (2009b). Feeling recovered and thinking about the good sides of one's work. Journal of Occupational Health Psychology, 14, 243-256. doi:10.1037/a0014933

Bledow, R., Schmitt, A., Frese, M., \& Kühnel, J. (2011). The affective shift model of work engagement. Journal of Applied Psychology, 96, 1246 1257. doi:10.1037/a0024532

Bless, H., Mackie, D. M., \& Schwarz, N. (1992). Mood effects on attitude judgments: Independent effects of mood before and after message elaboration. Journal of Personality and Social Psychology, 63, 585-595. doi:10.1037/0022-3514.63.4.585

Bolger, N., DeLongis, A., Kessler, R. C., \& Schilling, E. A. (1989). Effects of daily stress on negative mood. Journal of Personality and Social Psychology, 57, 808-818. doi:10.1037/0022-3514.57.5.808

Bower, G. H. (1981). Mood and memory. American Psychologist, 36, 129-148. doi:10.1037/0003-066X.36.2.129

Brotheridge, C. M., \& Lee, T. R. (2002). Testing a conservation of resources model of the dynamics of emotional labor. Journal of Occupational Health Psychology, 7, 57-67. doi:10.1037/1076-8998.7.1.57

Buchanan, T. W. (2007). Retrieval of emotional memories. Psychological Bulletin, 133, 761-779. doi:10.1037/0033-2909.133.5.761

Carver, C. S., \& Scheier, M. F. (1990). Origins and functions of positive and negative affect: A control process view. Psychological Review, 97, 19-35. doi:10.1037/0033-295X.97.1.19

Chi, N.-W., Grandey, A. A., Diamond, J. A., \& Krimmel, K. R. (2011) Want a tip? Service performance as a function of emotion regulation and extraversion. Journal of Applied Psychology, 96, 1337-1346. doi: $10.1037 / \mathrm{a} 0022884$

Cialdini, R. B. (2001). Influence: Science and practice. Needham Heights, MA: Allyn \& Bacon.

Cortina, L. M., \& Magley, V. J. (2009). Patterns and profiles of response to incivility in the workplace. Journal of Occupational Health Psychology, 14, 272-288. doi:10.1037/a0014934

Cortina, L. M., Magley, V. J., Hunter Williams, J., \& Langhout, R. D. (2001). Incivility in the workplace: Incidence and impact. Journal of Occupational Health Psychology, 6, 64-80. doi:10.1037/10768998.6.1.64

Côté, S. (2005). A social interaction model of the effects of emotion regulation on work strain. Academy of Management Review, 30, 509530. doi:10.5465/AMR.2005.17293692

Cropley, M., \& Purvis, L. J. M. (2003). Job strain and rumination about work issues during leisure time: A diary study. European Journal of Work and Organizational Psychology, 12, 195-207. doi:10.1080/ 13594320344000093

De Bloom, J., Geurts, S. A. E., Taris, T. W., Sonnentag, S., De Weerth, C., \& Kompier, M. A. J. (2010). Effects of vacation from work on health and well-being: Lots of fun, quickly gone. Work \& Stress, 24, 196-216.

De Cremer, D. (2002). The self-relevant implications of distribution rules: When self-esteem and acceptance are influenced by violations of the equity rule. Social Justice Research, 15, 327-339. doi:10.1023/A: 1021267007531

De Dreu, C. K. W., \& Beersma, B. (2005). Conflict in organizations: Beyond effectiveness and performance. European Journal of Work and Organizational Psychology, 14, 105-117. doi:10.1080/ 13594320444000227

De Dreu, C. K. W., van Dierendonck, D., \& Dijkstra, M. T. M. (2004). Conflict at work and individual well-being. International Journal of Conflict Management, 15, 6-26. doi:10.1108/eb022905

Dormann, C., \& Zapf, D. (2004). Customer-related social stressors and burnout. Journal of Occupational Health Psychology, 9, 61-82. doi: 10.1037/1076-8998.9.1.61

Dudenhöffer, S., \& Dormann, C. (2010, July). Customer-related social stressors and their consequences for service providers' negative and 
positive affective reactions. Paper presented at the seventh International Congress of Applied Psychology, Melbourne, Australia.

Eden, D. (2001). Vacations and other respites: Studying stress on and off the job. In C. L. Cooper \& I. T. Robertson (Eds.), International review of industrial and organizational psychology (pp. 121-146). Chichester: Wiley.

Edwards, J. R., \& Rothbard, N. P. (2000). Mechanisms linking work and family: Clarifying the relationship between work and family constructs. Academy of Management Review, 25, 178-199.

Etzion, D., Eden, D., \& Lapidot, Y. (1998). Relief from job stressors and burnout: Reserve service as a respite. Journal of Applied Psychology, 83, 577-585. doi:10.1037/0021-9010.83.4.577

Fritz, C., \& Sonnentag, S. (2006). Recovery, well-being, and performancerelated outcomes: The role of workload and vacation experiences. Journal of Applied Psychology, 91, 936-945. doi:10.1037/00219010.91.4.936

Fritz, C., Yankelevich, M., Zarubin, A., \& Barger, P. (2010). Happy, healthy, and productive: The role of detachment from work during nonwork time. Journal of Applied Psychology, 95, 977-983. doi: $10.1037 / \mathrm{a} 0019462$

Frone, M. R. (2000). Interpersonal conflict at work and psychological outcomes: Testing a model among young workers. Journal of Occupational Health Psychology, 5, 246-255. doi:10.1037/1076-8998.5.2.246

Giebels, E., \& Janssen, O. (2005). Conflict stress and reduced well-being at work: The buffering effect of third-party help. European Journal of Work and Organizational Psychology, 14, 137-155. doi:10.1080/ 13594320444000236

Grandey, A. A. (2000). Emotional regulation in the workplace: A new way to conceptualize emotional labor. Journal of Occupational Health Psychology, 5, 95-110. doi:10.1037/1076-8998.5.1.95

Grandey, A. A., \& Diamond, J. A. (2010). Interactions with the public: Bridging job design and emotional labor perspectives. Journal of Organizational Behavior, 31, 338-350. doi:10.1002/job.637

Grandey, A. A., Dickter, D. N., \& Sin, H.-P. (2004). The customer is not always right: Customer aggression and emotion regulation of service employees. Journal of Organizational Behavior, 25, 397-418. doi: $10.1002 /$ job. 252

Grandey, A. A., Kern, J. H., \& Frone, M. R. (2007). Verbal abuse from outsiders versus insiders: Comparing frequency, impact on emotional exhaustion, and the role of emotional labor. Journal of Occupational Health Psychology, 12, 63-79. doi:10.1037/1076-8998.12.1.63

Green, A. S., Rafaeli, E., Bolger, N., Shrout, P. E., \& Reis, H. T. (2006). Paper or plastic? Data equivalence in paper and electronic diaries. Psychological Methods, 11, 87-105. doi:10.1037/1082-989X.11.1.87

Gross, J. J. (1998). The emerging field of emotion regulation: An integrative review. Review of General Psychology, 2, 271-299. doi:10.1037/ 1089-2680.2.3.271

Hashimoto, T. (1995). Interpersonal conflicts as stressors: A perspective for stress reduction strategies. Japanese Journal of Experimental Social Psychology, 35, 185-193. doi:10.2130/jjesp.35.185

Hershcovis, M. S., Turner, N., Barling, J., Arnold, K. A., Dupré, K. E., Inness, M., . . Sivanathan, N. (2007). Predicting workplace aggression: A meta-analysis. Journal of Applied Psychology, 92, 228-238. doi: 10.1037/0021-9010.92.1.228

Hochschild, A. R. (1983). The managed heart. Berkeley, CA: University of California Press.

Hox, J. J. (2002). Multilevel analysis: Techniques and applications. Mahwah, NJ: Erlbaum.

Hülsheger, U. R., \& Schewe, A. F. (2011). On the costs and benefits of emotional labor: A meta-analysis of three decades of research. Journal of Occupational Health Psychology, 16, 361-389. doi:10.1037/ a0022876

Ilies, R., Johnson, M. D., Judge, T. A., \& Keeney, J. (2011). A withinindividual study of interpersonal conflict as a work stressor: Disposi- tional and situational moderators. Journal of Organizational Behavior, 32, 44-64. doi:10.1002/job.677

Ilies, R., Schwind, K. M., Wagner, D. T., Johnson, M. D., DeRue, D. S., \& Ilgen, D. R. (2007). When can employees have a family life? The effects of daily workload and affect on work-family conflict and social behaviors at home. Journal of Applied Psychology, 92, 1368-1379. doi:10.1037/0021-9010.92.5.1368

International Labour Office. (2007). Global employment trends brief. Retrieved from http://www.ilo.org/wcmsp5/groups/public/@ed_emp/ @emp_elm/@trends/ documents/publication/wcms_114295.pdf

Judge, T. A., Woolf, E. F., \& Hurst, C. (2009). Is emotional labor more difficult for some than for others? A multilevel, experience-sampling study. Personnel Psychology, 62, 57-88. doi:10.1111/j.17446570.2008.01129.x

Kline, R. B. (2005). Principles and practice of structural equation modeling. New York, NY: Guilford Press.

Lange, A., Richard, R., Gest, A., de Vries, M., \& Lodder, L. (1998). The effects of positive self-instruction: A controlled trial. Cognitive Therapy and Research, 22, 225-236. doi:10.1023/A:1018740725281

Martin, L. L., \& Tesser, A. (1996). Some ruminative thoughts. In R. S. Wyer, Jr. (Ed.), Ruminative thoughts (pp. 1-47). Hillsdale, NJ: Erlbaum.

Martin, L. L., \& Tesser, A. (2006). Extending the goal progress theory of rumination: Goal reevaluation and growth. In L. J. Sanna \& E. C. Chang (Eds.), Judgments over time: The interplay of thoughts, feelings, and behaviors (pp. 145-162). New York, NY: Oxford University Press.

Merz, E. L., \& Roesch, S. C. (2010). Modeling trait and state variation using multilevel factor analysis with PANAS daily diary data. Journal of Research in Personality, 45, 2-9.

Mroczek, D. K., \& Almeida, D. M. (2004). The effect of daily stress, personality, and age on daily negative affect. Journal of Personality, 72, 355-378. doi:10.1111/j.0022-3506.2004.00265.x

Mueller, S., \& Tschan, F. (2011). Consequences of client-initiated workplace violence: The role of fear and perceived prevention. Journal of Occupational Health Psychology, 16, 217-229. doi:10.1037/a0021723

Muthén, L. K., \& Muthén, B. O. (1998-2004). Mplus user's guide (3rd ed.). Los Angeles, CA: Author.

Nolen-Hoeksema, S., \& Morrow, J. (1993). Effects of rumination and distraction on naturally occurring depressed mood. Cognition \& Emotion, 7, 561-570. doi:10.1080/02699939308409206

Preacher, K. J., \& Hayes, A. F. (2004). SPSS and SAS procedures for estimating indirect effects in simple mediation models. Behavior Research Methods, Instruments \& Computers, 36, 717-731.

Raudenbush, S. W., Bryk, A., Cheong, Y. F., \& Congdon, R. (2004). HLM6: Hierarchical linear and nonlinear modeling. Chicago, IL: Scientific Software International.

Rupp, D. E., \& Spencer, S. (2006). When customers lash out: The effects of customer interactional injustice on emotional labor and the mediating role of discrete emotions. Journal of Applied Psychology, 91, 971-978. doi:10.1037/0021-9010.91.4.971

Sanz-Vergel, A. I., Demerouti, E., Bakker, A. B., \& Moreno-Jiménez, B. (2011). Daily detachment from work and home: The moderating effect of role salience. Human Relations, 64, 775-799. doi:10.1177/ 0018726710393368

Schwarz, N. (1990). Feelings as information: Informational and motivational functions of affective states. In R. M. Sorrentino \& E. T. Higgins (Eds.), Handbook of motivation and cognition: Foundation of social behavior (Vol. 2, pp. 527-561). New York, NY: Guilford Press.

Schwarz, N., \& Clore, G. L. (1983). Mood, misattribution, and judgments of well-being: Informative and directive functions of affective states. Journal of Personality and Social Psychology, 45, 513-523. doi: 10.1037/0022-3514.45.3.513

Semmer, N. K., Jacobshagen, N., Meier, L. L., \& Elfering, A. (2007). Occupational stress research: The "stress-as-offense-to-self" perspective. In S. McIntyre \& J. Houdmont (Eds.), Occupational health psy- 
chology: European perspectives on research, education, and practice (Vol. 2, pp. 41-58). Nottingham, England: Nottingham University Press. Siltaloppi, M., Kinnunen, U., \& Feldt, T. (2009). Recovery experiences as moderators between psychosocial work characteristics and occupational well-being. Work \& Stress, 23, 330-348. doi:10.1080/ 02678370903415572

Sliter, M. T., Pui, S. Q., Sliter, K. A., \& Jex, S. M. (2011). Differential effects of interpersonal conflict from customers and coworkers: Trait anger as a moderator. Journal of Occupational Health Psychology, 16, 424-440. doi:10.1037/a0023874

Song, Z., Foo, M. D., \& Uy, M. (2008). Mood spillover and crossover among dual-earner couples: A cell phone event sampling study. Journal of Applied Psychology, 93, 443-452. doi:10.1037/0021-9010.93.2.443

Sonnentag, S., \& Bayer, U.-V. (2005). Switching off mentally: Predictors and consequences of psychological detachment from work during offjob time. Journal of Occupational Health Psychology, 10, 393-414. doi:10.1037/1076-8998.10.4.393

Sonnentag, S., Binnewies, C., \& Mojza, E. J. (2008). "Did you have a nice evening?" A day-level study on recovery experiences, sleep, and affect. Journal of Applied Psychology, 93, 674-684. doi:10.1037/00219010.93.3.674

Sonnentag, S., \& Fritz, C. (2007). The Recovery Experience Questionnaire: Development and validation of a measure for assessing recuperation and unwinding from work. Journal of Occupational Health Psychology, 12, 204-221. doi:10.1037/1076-8998.12.3.204

Sonnentag, S., \& Kruel, U. (2006). Psychological detachment from work during off-job time: The role of job stressors, job involvement, and recovery-related self-efficacy. European Journal of Work and Organizational Psychology, 15, 197-217. doi:10.1080/13594320500513939

Spector, P. E., \& Bruk-Lee, V. (2008). Conflict, health, and well-being. In C. K. W. De Dreu \& M. J. Gelfand (Eds.), The psychology of conflict and conflict management in organizations (pp. 267-288). San Francisco, CA: Jossey-Bass.

Spector, P. E., \& Jex, S. M. (1998). Development of four self-report measures of job stressors and strain: Interpersonal Conflict at Work Scale, Organizational Constraints Scale, Quantitative Workload Inventory, and Physical Symptoms Inventory. Journal of Occupational Health Psychology, 3, 356-367. doi:10.1037/1076-8998.3.4.356

Tennen, H., Affleck, G., Coyne, J. C., Larsen, R. J., \& DeLongis, A. (2006). Paper and plastic in daily diary research. Psychological Methods, 11, 112-118. doi:10.1037/1082-989X.11.1.112
Thomas, J. L., Bliese, P. D., \& Jex, S. M. (2005). Interpersonal conflict and organizational commitment: Examining two levels of supervisory support as multilevel moderators. Journal of Applied Social Psychology, 35, 2375-2398. doi:10.1111/j.1559-1816.2005.tb02107.x

Totterdell, P., \& Holman, D. (2003). Emotion regulation in customer service roles: Testing a model of emotional labor. Journal of Occupational Health Psychology, 8, 55-73. doi:10.1037/1076-8998.8.1.55

Tschan, F., Rochat, S., \& Zapf, D. (2005). It's not only clients: Studying emotion work with clients and co-workers with an event-sampling approach. Journal of Occupational and Organizational Psychology, 78, 195-220. doi:10.1348/096317905X39666

Watkins, E. R. (2008). Constructive and unconstructive repetitive thought. Psychological Bulletin, 134, 163-206. doi:10.1037/0033-2909.134 .2 .163

Watson, D., Clark, L. A., \& Tellegen, A. (1988). Development and validation of brief measures of positive and negative affect: The PANAS scales. Journal of Personality and Social Psychology, 54, 1063-1070. doi:10.1037/0022-3514.54.6.1063

Weiss, H. M., \& Cropanzano, R. (1996). Affective events theory: A theoretical discussion of the structure, causes and consequences of affective experiences at work. In B. M. Staw \& L. L. Cummings (Eds.), Research in organizational behavior: An annual series of analytical essays and critical reviews (Vol. 18, pp. 1-74). Oxford, England: Elsevier.

Xanthopoulou, D., Bakker, A., Heuven, E., Demerouti, E., \& Schaufeli, W. B. (2008). Working in the sky: A diary study on work engagement among flight attendants. Journal of Occupational Health Psychology, 13, 345-356. doi:10.1037/1076-8998.13.4.345

Zapf, D. (2002). Emotion work and psychological well-being: A review of the literature and some conceptual considerations. Human Resource Management Review, 12, 237-268. doi:10.1016/S1053-4822(02)00048-7

Zapf, D., Vogt, C., Seifert, C., Mertini, H., \& Isic, A. (1999)., Emotion work as a source of stress: The concept and development of an instrument. European Journal of Work and Organizational Psychology, 8, 371-400. doi:10.1080/135943299398230

Received August 22, 2011

Revision received April 5, 2012

Accepted April 6, 2012 